\title{
Primary Uveal Melanoma Metastasizing to the Intraconal Space of the Contralateral Orbit: A Case Report
}

\author{
Cyrus M. Ayahao, MD, ${ }^{1}$ Eulina L. Lagdao, MD, MHA ${ }^{1}$ and Roland Joseph D. Tan, MD, $\mathrm{MS}^{1,2,3}$ \\ ${ }^{1}$ Department of Ophthalmology, Baguio General Hospital and Medical Center, Baguio City, Philippines \\ ${ }^{2}$ Department of Ophthalmology and Visual Sciences, Philippine General Hospital, University of the Philippines Manila, Manila, Philippines \\ ${ }^{3}$ College of Medicine, University of the Philippines Manila, Manila, Philippines
}

\begin{abstract}
Objective. We present an extremely rare case of primary uveal melanoma (PUM) metastasizing to the intraconal space of the contralateral orbit without involving the liver.

Case summary. This is a case of a 66-year-old woman who underwent enucleation of the right eye for an intraocular mass five years prior to consult and had a histopathologic diagnosis of spindle cell melanoma. She had no skin lesions nor distant metastasis on systemic work-up. Five years later, she came back for gradual loss of vision in the left eye associated with eye pain and progressive proptosis from a intraconal orbital mass. Excision biopsy of said mass revealed an epithelioid cell melanoma. Again, she has no skin lesions nor liver involvement.
\end{abstract}

Conclusion. PUM metastasizing to the intraconal space of the contralateral orbit without liver involvement as seen in our patient is exceedingly rare. Despite differences in the histopathologic characteristics, the orbital melanoma was presumed to be metastasis due to the rarity of a second primary and its delayed presentation compared to the PUM.

Keywords: melanoma, metastasis, orbital melanoma, intraconal, primary uveal melanoma

\section{INTRODUCTION}

Primary uveal melanoma (PUM) is a rare type of melanoma with an incidence of 4.3 cases per million people with 99\% occurring in Caucasians. ${ }^{1-3}$ Its incidence in Asians is 10 times lower at $0.4-0.6$ per million people. ${ }^{1,4}$ PUM, similar to primary cutaneous melanoma, is known for systematic metastasis. Half of PUM patients had systemic metastasis. ${ }^{5}$ The liver is the most common site of metastasis at $95 \%$ of the time. Primary uveal melanoma (PUM) as a source of metastasis to the contralateral orbit particularly in the intraconal space without involving the liver is extremely rare. ${ }^{5-7}$

\section{CASE REPORT}

This is a case of a 66-year-old woman with a one-

Poster presented in the Annual Resident Research Presentation on January 15, 2021, at Baguio General Hospital and Medical Center, Baguio City, Philippines.

Corresponding author: Roland Joseph D. Tan Baguio General Hospital and Medical Center Baguio City 2600, Philippines

Email:rdtan@up.edu.ph month history of gradual loss of vision in the left eye with associated eye pain and proptosis. Five years prior to consult, she underwent enucleation of the right eye for an intraocular mass diagnosed as a spindle cell uveal melanoma. She did not undergo radiotherapy or immunotherapy at that time since there was no extrascleral spread. She did not have cutaneous melanoma on dermatologic survey. Her systemic 


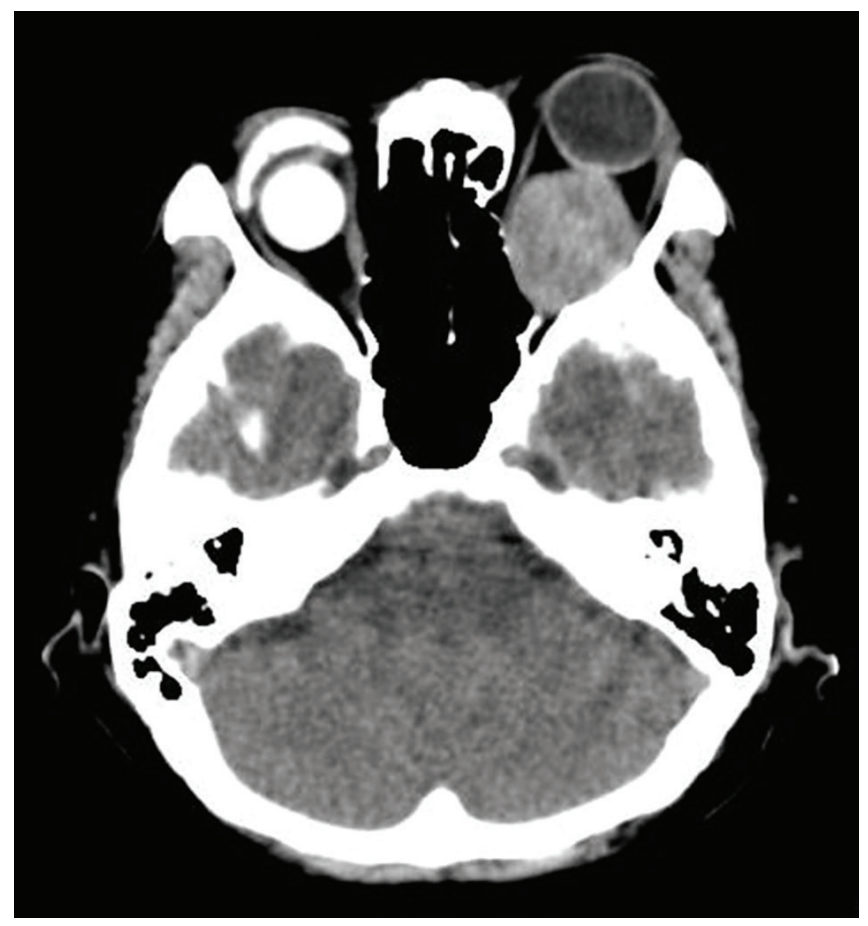

Figure 1. Axial computed tomography scan of the orbit showing a large mass on the left orbit impinging the optic structures with noted proptosis of the left eye. An orbital implant and a conformer are seen on the right orbit.

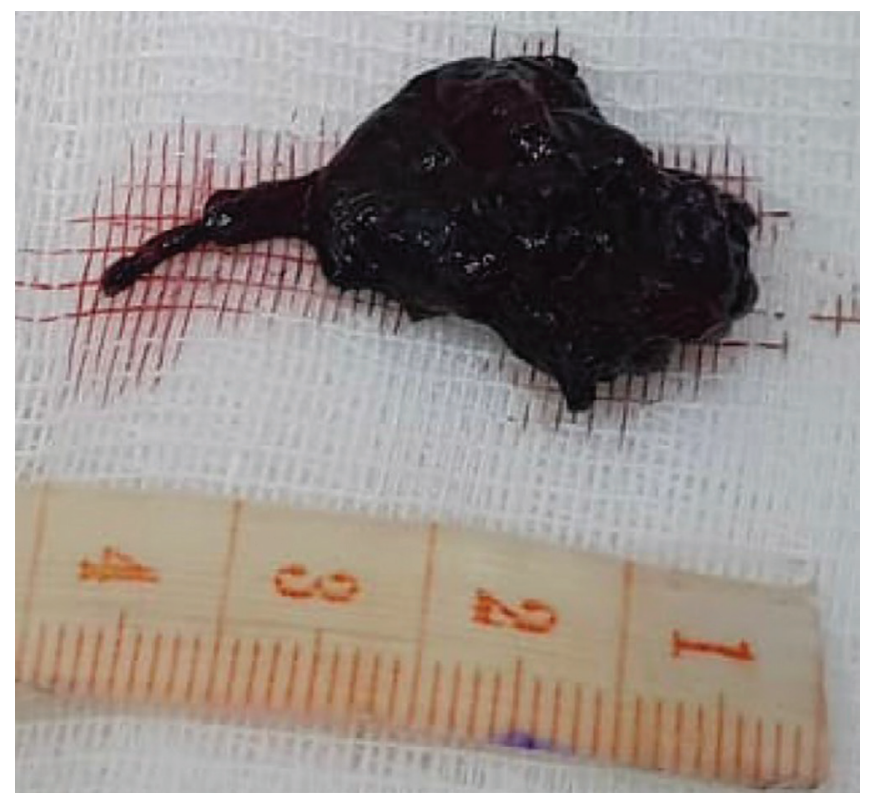

Figure 2. An irregularly-shaped, well-delineated, soft, dark blue mass filed with jet-black fluid that is non-adherent to other structures was excised from the left orbit. work-up, which included computed tomography of the head and abdomen, did not show any metastasis.

On vision examination, the left eye already has no light perception. Her left eye was proptosed and was hard on palpation. There were no pigmentary changes such as nevus of Ota, blue cellular nevus or oculodermal melanosis in the ocular adnexa. Fundoscopy revealed a hyperemic disc with indistinct borders and flame-shaped hemorrhages at the peripapillary area. She has an artificial eye on the right orbit and upon removal, the conjunctiva behind was normal without any palpable mass. She did not have cutaneous melanoma based on dermatologic survey.

Orbital computed tomography revealed a $2.8 \times 2.5$ $\mathrm{cm}$ well-circumscribed homogenous intraconal mass impinging on the optic structures on the left eye and an orbital implant with conformer in the right orbit (Figure 1). An excisional biopsy thru a lateral orbitotomy was done which revealed an irregularly-shaped, well-delineated, soft, dark blue mass filed with jet-black fluid that was nonadherent to other structures (Figure 2). Histopathological examination revealed predominance of variably-sized, pigmented epithelioid cells with high nuclear-to-cytoplasm ratio (Figure 3). HMB-45 staining, a stain highly specific for malignant melanoma, yielded positive results (Figure 4).

Review of previously enucleated right eye showed an ill-defined mass composed predominantly of spindle cells with prominent nucleoli, surrounding cytoplasm with dark brown granular pigments with occasional mitotic figures. The tumor extended to the choroid, pushing the retina anteriorly, and invading the surrounding sclera and lamina cribrosa but not extending beyond the latter. Perineural and perivascular invasions were noted.

She underwent systemic metastasis work-up including a holo-abdominal computed tomography scan which revealed a normal liver.

\section{DISCUSSION}

Primary uveal melanoma (PUM) metastasizing to the contralateral orbit has been reported in only 13 cases, none of which came from the Philippines or Asia. ${ }^{6}$ Most of these contralateral orbital metastases primarily involved the extraocular muscles with none reported to be confined in the intraconal space similar to our patient. ${ }^{8}$ The appearance of the mass on orbital CT and its location in the intraconal area made us initially consider a cavernous hemangioma. However, due to the history of a PUM, metastasis was instead considered.

Our case is also uncommon in that both melanomas exhibited different histopathologic characteristics. Melanoma is notorious for its great variability in its histologic features. It can be composed of epithelioid, spindle-shaped, or mixed type of cells. The cell cytoplasm can be eosinophilic, basophilic, foamy, signet-ring type, rhabdoid, oncocytic, or completely clear. Melanin can be abundant, scanty, or absent. ${ }^{9}$ 

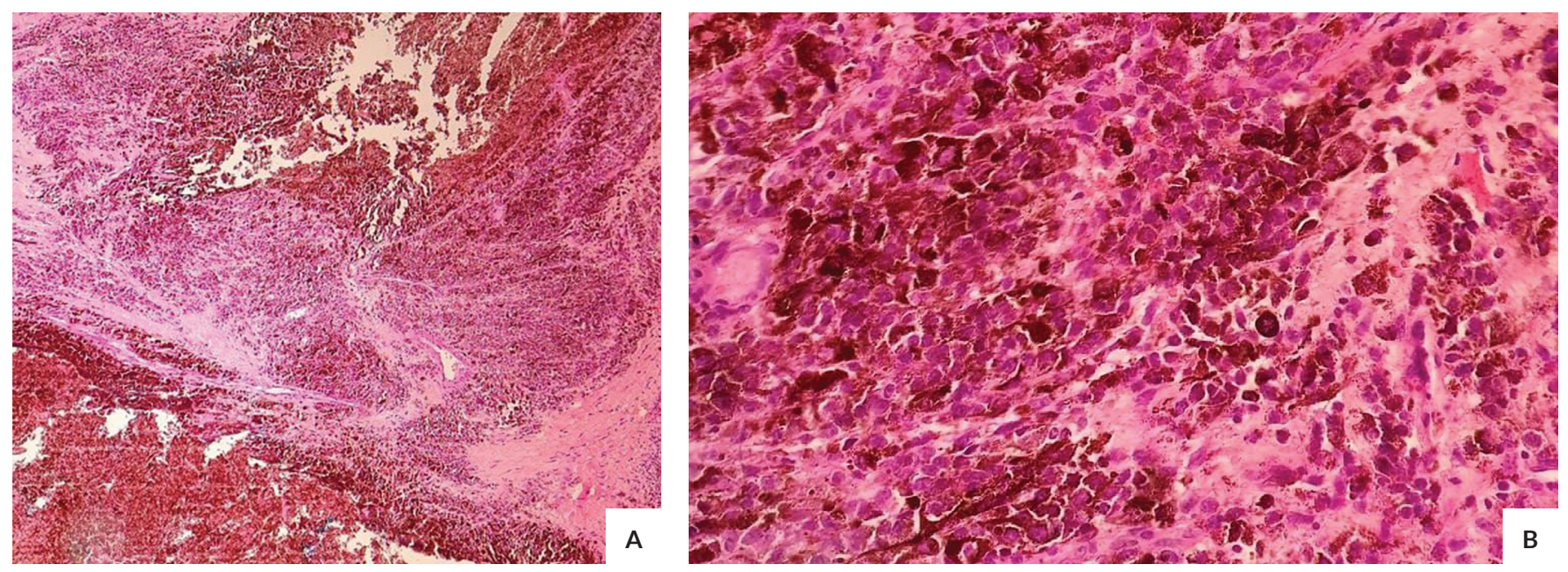

Figure 3. Histopathologic analysis of the orbital melanoma. Hematoxylin and eosin stain on LPO view (A) revealed predominantly epithelioid cells with high nuclear to cytoplasm ratio. On HPO view (B), it is composed of large cells showing atypia, enlarged and pleomorphic with prominent nucleoli, surrounded by eosinophilic, granular cytoplasm. The surrounding stroma appears pigmented.

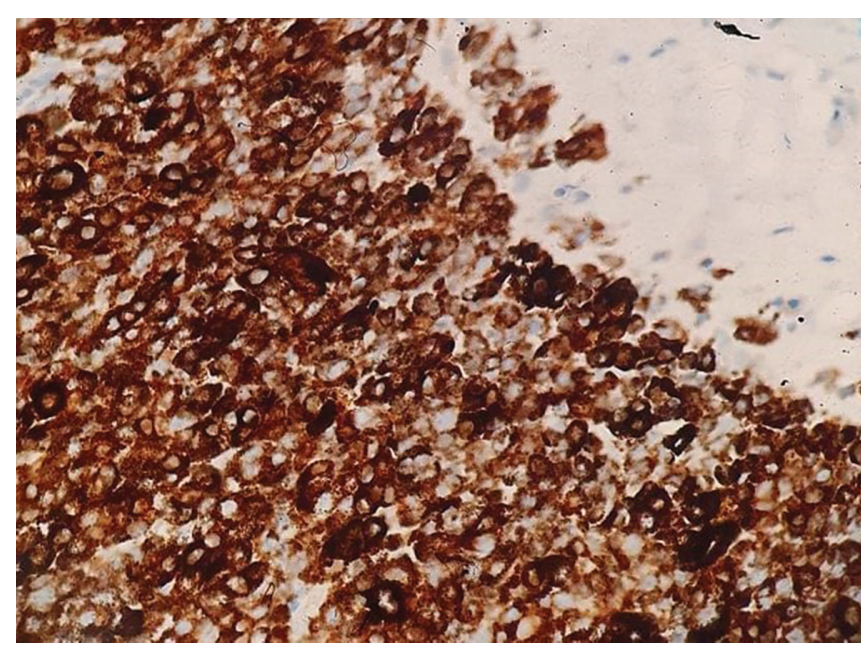

Figure 4. HMB45 stain of the excised mass revealing positive results among the cells of interest.

In our patient, the histopathologic results of the left orbital mass revealed melanoma with predominance of epithelioid cells. It was composed of large cells showing atypia, enlarged and pleomorphic with prominent nucleoli that was surrounded by eosinophilic granular cytoplasm. HMB-45 staining, a stain highly specific for metastatic melanoma, was positive among cells of interest. ${ }^{10}$ On the other hand, the enucleated right eye showed melanoma with predominance of spindle cells and occasional mitotic figures. These histologic features were not identical with the mass in the left orbit. However, a second primary orbital melanoma was not considered despite having two different histologic features due to its rarity and the delay in presentation of the orbital mass. ${ }^{11}$ Although there are a few reported cases of simultaneous bilateral uveal melanoma and coexistent primary uveal and primary cutaneous melanoma, there are no reported cases, to our knowledge, of a coexistent primary uveal and primary orbital melanoma. ${ }^{11,12}$

\section{CONCLUSION}

This is a rare case of a PUM metastasizing to the intraconal space of the contralateral orbit and presenting with different histological characteristics after five years without involving the liver in an older Filipino woman.

\section{Consent}

The patient consented to the publication of this case report.

\section{Statement of Authorship}

All authors participated in data collection and analysis, and approved the final version submitted.

\section{Author Declaration}

All authors declared no conflicts of interest.

\section{Funding Source}

None.

\section{REFERENCES}

1. Singh A, Turell M, Topham A. Uveal melanoma: trends in incidence, treatment, and survival. Ophthal. 2011; 118(9):1881-5.

2. Singh A, Bergman L, Seregard S. Uveal melanoma: epidemiologic aspects. Ophthal Clinics North Am. 2005; 18(1):75-84.

3. Shields C, Kaliki S, Cohen M, Shields P, Furuta M, Shields J. Prognosis of uveal melanoma based on race in 8100 patients: The 2015 Doyne Lecture. Eye. 2015; 29(8):1027-35.

4. Park SJ, Oh CM, Kim BW, Woo SJ, Cho H, Park KH. Nationwide Incidence of Ocular Melanoma in South Korea by Using the National Cancer Registry Database (1999-2011). Inv Ophthal Visual Sci. 2015; 56(8):4719. 
5. Bedikian A, Legha S, Mavligit G, Carrasco C, Khorana S, Plager C, et al. Treatment of uveal melanoma metastatic to the liver: a review of the MD Anderson Cancer Center experience and prognostic factors. Cancer. 1995; 76:1665-70.

6. Connolly G, Wladis E, Masselam K, Weinberg D. Contralateral orbital melanoma 28 years following enucleation for choroidal melanoma. Orbit. 2007; 26(4):291-4.

7. Kath R, Hayungs J, Bornfeld N, Sauerwein W, Hoffken K, Seeber S. Prognosis and treatment of disseminated uveal melanoma. Cancer. 1993;72(7):2219-23.

8. McElnea E, Stevenson L, La Rosa C, Liew S, Hardy T. Choroidal melanoma metastatic to the contralateral medial rectus after orbital exenteration. Turk J Ophthalmol. 2019; 49(5):305-9. doi:10.4274/tjo. galenos.2019.35589
9. Goldblum J, Lamps L, McKenney J, Myers J. Rosai and Ackerman's Surgical Pathology - 2 Volume Set. 11th ed. Philadelphia, PA: Elsevier; 2017.

10. McDonnell J, Sun Y, Wagner D. HMB-45 Immunohistochemical Staining of Conjunctival Melanocytic Lesions. Ophthalmol. 1991; 98(4): 453-8. doi.org/10.1016/S0161-6420(91)32281-4

11. Ascaso F, Cascante J, Castillo J, Arraiza A, Palomar A. Simultaneous bilateral primary choroidal melanoma. Eur J Ophthalmol. 1996; 6(1):87-9.

12. ScullJ,Alcocer C,Deschênes J, Burnier M. Primary choroidal melanoma in a patient with previous cutaneous melanoma. Arch Ophthalmol. 1997; b115(6):796-8. doi:10.1001/archopht.1997.01100150798019

\title{
Have you read the current trends in
} Medical and Health Research in the Philippines?

\section{Acta Medica Philippina The National Health Science Journal}

\author{
Access Online: www.actamedicaphilippina.upm.edu.ph
}

